\title{
Etiology of Phytophthora drechsleri and P. nicotianae (=P. parasitica) Diseases Affecting Floriculture Crops
}

\author{
K. H. Lamour, Department of Entomology and Plant Pathology, The University of Tennessee, Knoxville 37996- \\ 4560; M. L. Daughtrey, Long Island Horticulture Research and Extension Center, Cornell University, Riverhead, \\ NY 11901-1115; D. M. Benson and J. Hwang, Department of Plant Pathology, North Carolina State University, \\ Raleigh 27695-7629; and M. K. Hausbeck, Department of Plant Pathology, Michigan State University, East Lans- \\ ing 48824-1312
}

\begin{abstract}
Lamour, K. H., Daughtrey, M. L., Benson, D. M., Hwang, J., and Hausbeck, M. K. 2003. Etiology of Phytophthora drechsleri and P. nicotianae (=P. parasitica) diseases affecting floriculture crops. Plant Dis. 87:854-858.

Phytophthora nicotianae and $P$. drechsleri isolates $(n=413)$ recovered from eight floricultural hosts at 11 different production sites were described according to compatibility type, resistance to mefenoxam, and amplified fragment length polymorphism (AFLP) profiles. Sample sizes ranged from 2 to 120 . In all cases, isolates recovered from a single facility had the same compatibility type and resistance to mefenoxam. AFLP analysis indicated that six clonal lineages of $P$. nicotianae and two clonal lineages of $P$. drechsleri were responsible for the 11 epidemics and that isolates recovered from the same facility were identical. A single clone of $P$. nicotianae was recovered from snapdragons at two field production sites in the southeastern United States receiving seedlings from the same source. This clone persisted at one site from 2000 to 2001. Another clone was recovered from verbena at three separate greenhouse facilities where one facility was supplying verbena to the other two. These results suggest that asexual reproduction of these pathogens plays an important role in epidemics and spread may occur between distant facilities via movement of plants.
\end{abstract}

Phytophthora nicotianae Breda de Haan (=P. parasitica Dastur) and $P$. drechsleri Tucker are two oomycetes that cause root rot, crown rot, and foliar blight on a variety of ornamental plants produced in the United States $(4,21)$. Losses can be severe in production sites where ample water, abundant host tissue, and warm temperatures offer favorable conditions for disease development. Recirculating irrigation water systems are used by many producers of ornamental crops in the United States to decrease the environmental impacts of

Corresponding author: K. H. Lamour

E-mail: klamour@utk.edu

This research was funded through Specific Cooperative Agreements between the USDA-ARS Plant Protection Research Unit, Ithaca, NY, and the Michigan State University Department of Plant Pathology, E. Lansing, MI (SCA \#58-1907-0034), and the Cornell University Department of Plant Pathology, Ithaca, NY (SCA \#58-1907-0035); and through a Specific Cooperative Agreement between the USDA-ARS Plant Science Research Unit, Raleigh, NC, and the North Carolina State University Department of Plant Pathology, Raleigh, NC (SCA \#58-6645-0-233). These agreements were established by the USDAARS as part of the Floriculture and Nursery Research Initiative.

Accepted for publication 27 February 2003.

Publication no. D-2003-0509-02R

(C) 2003 The American Phytopathological Society chemical run off and to lower production costs by conserving water. This practice may play a role in inoculum dispersal (16).

Sanitation is an essential part of preventing and limiting disease development and includes the removal of extraneous plant debris; sterilizing pots, potting mixes, and production surfaces; and the use of disease-free plant material. Many producers routinely treat plants with the phenylamide fungicides (PAFs), mefenoxam or its similarly acting isomer metalaxyl, and the efficacy of these compounds in controlling Phytophthora and Pythium spp.-induced diseases has been documented $(7,21)$. However, resistance to PAFs has been reported for isolates of Phytophthora nicotianae recovered from vinca in California $(5,7)$ and citrus trees in Florida (17).

$P$. nicotianae and $P$. drechsleri are heterothallic, requiring $\mathrm{A} 1$ and $\mathrm{A} 2$ compatibility types (=mating types) to complete the sexual stage and produce thickwalled oospores. Outcrossing has the potential to generate novel genotypes and maintain genetic diversity (10). Asexual reproduction is accomplished by hyphal fragments, sporangia which can germinate directly or release motile zoospores in water, and thick-walled chlamydospores. Chlamydospores have been reported for some isolates of $P$. drechsleri and commonly are seen in culture with $P$. nicotianae (13). Asexual reproduction results in the dissemination of genetically identical clones. Water is an important environmental variable for disease development (2). Under warm, wet conditions, numerous spores may be produced on infected plants and lead to multiple cycles of infection and spread within a short period of time (15).

Once an epidemic has developed in a production site, it often is difficult to determine how the causal organism was introduced, how it is spreading, and if it is persisting over time. One strategy for resolving these questions is to characterize the distribution of genetically unique individuals in space and time. A variety of molecular tools are now available for detecting differences between organisms at the DNA level, and these are especially helpful for studying organisms such as $P$. nicotianae and $P$. drechsleri, which have few readily assessable phenotypic markers (14). Tracking the incidence and distribution of unique strains has provided insight into the epidemiology of other heterothallic Phytophthora spp., such as $P$. infestans on potato and tomato and $P$. capsici on cucurbit and solanaceous hosts. Studies of $P$. infestans suggest that clonal lineages may be spread globally through the movement of potato tubers and persist for years (9). For P. capsici, clonal reproduction appears to be limited to single fields in a growing season and oospores appear to play a key role in survival from year to year (12).

Our objective was to identify species of Phytophthora causing epidemics on floricultural hosts in selected U.S. production facilities and to investigate spread within facilities.

\section{MATERIALS AND METHODS}

Isolate recovery. Plants with symptoms typical of infection by Phytophthora spp. (i.e., brown-black lesions at the soil line and discolored, softened roots) were collected from 11 production sites (nine greenhouses and two fields) located in the eastern United States. Plants were collected from multiple locations within a production facility. Sample sets were labeled according to location and year of sampling. Isolation from diseased plant material was made onto BARP (benomyl, 25 ppm; ampicillin, 100 ppm; rifampicin, 
30 ppm; and pentachloronitrobenzene, 100 ppm)-amended UCV8 ( $840 \mathrm{ml}$ of distilled water, $163 \mathrm{ml}$ of unclarified V8 juice, $3 \mathrm{~g}$ of $\mathrm{CaCO}_{3}$, and $16 \mathrm{~g}$ of agar) plates or onto water agar.

To obtain single hyphal-tip cultures, the uppermost portion of a 7-mm plug of an expanding colony was transferred to the surface of a water agar plate amended with benomyl at $25 \mathrm{ppm}$, ampicillin at $100 \mathrm{ppm}$, and rifampicin at $30 \mathrm{ppm}$. A sterilized 10mm cap cut from a standard 2-ml microfuge tube then was placed over the plug and gently pressed down. This technique forced the mycelium to ramify through the amended water agar. After 2 to 3 days, plates were inspected under a dissecting microscope at $\times 25$ magnification and a single hyphal branch was transferred to RA (rifampicin, $30 \mathrm{ppm}$ and ampicillin, 100 ppm)-UCV8 plates and transfers were repeated bimonthly. For long-term storage, a 7-mm plug of actively growing mycelium from each culture was placed into a 1.5-ml microfuge tube with one sterilized hemp seed and $1 \mathrm{ml}$ of sterile distilled water (SDW). Isolates then were incubated for 2 to 3 weeks at 23 to $25^{\circ} \mathrm{C}$ before being stored at $15^{\circ} \mathrm{C}$.

Compatibility type and mefenoxam resistance determination. To determine compatibility type, agar plugs from the edge of an expanding single hyphal-tip colony were placed at the center of UCV8 plates approximately $2 \mathrm{~cm}$ from $P$. capsici isolates OP97 (A1) and SP98 (A2) and incubated in the dark at 23 to $25^{\circ} \mathrm{C}$ for 3 to 6 days. Following incubation, compatibility type was determined by examining the plates for oospore production.

To determine mefenoxam resistance, agar plugs from the edge of actively expanding single hyphal-tip colonies were placed at the center of 100-by-15-mm UCV8 plates amended with mefenoxam at 0 or 100 ppm (Ridomil Gold EC, Syn- genta, Subdue Maxx; Syngenta, Greensboro, NC; $48 \%$ a.i. suspended in SDW was added to UCV8 cooled to $49^{\circ} \mathrm{C}$ ). Culture plates were incubated at 23 to $25^{\circ} \mathrm{C}$ for 3 days. Percentage of growth of an isolate on amended media was calculated by subtracting the initial plug diameter (7 $\mathrm{mm}$ ) from the diameter of each colony and dividing the average diameter of the colony on amended plates by the average diameter of the colony on unamended control plates. All tests were conducted at least twice. An isolate was scored as sensitive (S) if growth at $100 \mathrm{ppm}$ was $<30 \%$ of the control, intermediately resistant (IR) if growth was between 30 and $90 \%$ of the control, and resistant (R) if growth was $>90 \%$ of the control (11).

DNA extraction. Two 7-mm plugs of actively expanding mycelium were transferred to approximately $15 \mathrm{ml}$ of RAUCV8 broth in 100-by-15-mm petri dishes and incubated in the dark for 3 days at 23 to $25^{\circ} \mathrm{C}$. Mycelial mats were washed with distilled water and dried briefly under vacuum before being frozen at $-20^{\circ} \mathrm{C}$ and lyophilized. Lyophilized mats were ground with a sterile mortar and pestle. Whole genomic DNA from approximately $50 \mathrm{mg}$ of ground mycelium was extracted using a Qiagen Dneasy Plant Mini Kit (Qiagen Inc., Valencia, CA) according to the manufacturer's directions. DNA was quantified with Nucleic Acid QuickSticks (Clontech, Palo Alto, CA) according to the manufacturer's directions or on $1.5 \%$ agarose gels.

Identification to species. Species were identified using morphological characters and ribosomal DNA sequencing. Actively expanding mycelium from single hyphaltip cultures (7-mm plugs) were transferred to 100 -by-15-mm water agar plates (two plates per isolate) and one of the plates was flooded with SDW. Plates were incubated overnight under continuous fluorescent lighting at room temperature and spo- rangial morphology was observed. Internal transcribed spacer (ITS)-based identification was completed according to the methods described by Cooke et al. (3). A single round of polymerase chain reaction (PCR) with primers ITS6 (5' GAAGGTGAAGTCGTAACAAGC) and ITS4 (5' TCCTCCGCTTATTGATATGC) was performed using $100 \mathrm{ng}$ of DNA, $0.5 \mu \mathrm{m}$ of each primer, and $17.5 \mu \mathrm{l}$ of Core Mix from Applied Biosystems (Foster City, CA) in a total volume of $20 \mu \mathrm{l}$. The PCR cycle consisted of a single cycle of $94^{\circ} \mathrm{C}$ for 3 min followed by 35 cycles of $65^{\circ} \mathrm{C}$ for 30 $\mathrm{s}, 72^{\circ} \mathrm{C}$ for $60 \mathrm{~s}$, and $94^{\circ} \mathrm{C}$ for $30 \mathrm{~s}$, and a final single step at $72^{\circ} \mathrm{C}$ for $10 \mathrm{~min}$. PCR products were purified using the QIAquick PCR Purification Kit (Quiagen, Inc.) according to the manufacturer's directions, and a portion of the product then was resolved on a $1.5 \%$ agarose gel $(80 \mathrm{~V}$ for 3 h). PCR products were sequenced at the Genomics Technology Support Facility at Michigan State University using primers ITS6 and ITS4 and compared with nucleotide sequences in GenBank.

Amplified fragment length polymorphism fingerprinting. Genomic DNA from a subset of the isolates was analyzed using amplified fragment length polymorphism (AFLP) markers. Approximately $100 \mathrm{ng}$ of DNA was subjected to a restriction/ligation reaction, preselective amplification, and selective amplifications using the PCR core mix, adaptor sequences, core primer sequences, and fluorescence-labeled primers provided in the Perkin-Elmer Applied Biosystems (PE/ABI) AFLP Microbial Fingerprinting Kit (PerkinElmer Corp., Foster City, CA) and performed exactly as described in the PE/ABI AFLP Microbial Fingerprinting protocol part \#402977 Rev A (20). All PCR reactions were performed using an $\mathrm{MJ}$ Research Minicycler (MJ Research Inc., Waltham, MA) in 0.2-ml tubes according

Table 1. Summary data for Phytophthora nicotianae (= P. parasitica) and P. drechsleri isolates collected from floriculture production facilities in the United States during 2000 and 2001

\begin{tabular}{|c|c|c|c|c|c|}
\hline Facility $^{\mathbf{a}}$ & Hosts & Phytophthora spp. ${ }^{\mathrm{b}}$ & No. of isolates ${ }^{c}$ & Compatibility type & $\mathbf{M R}^{\mathbf{d}}$ \\
\hline $1-2000$ & Poinsettia, Euphorbia pulcherrima & P. drechsleri & $52(10)$ & $\mathrm{A} 1$ & $\mathrm{~S}$ \\
\hline $2-2001$ & Poinsettia, E. pulcherrima & P. drechsleri & $17(8)$ & A1 & IR \\
\hline $3-2000$ & Snapdragon, Antirrhinum majus & P. nicotianae & $120(50)$ & $\mathrm{A} 2$ & $\mathrm{~S}$ \\
\hline $4-2000$ & Snapdragon, A. majus & P. nicotianae & $75(30)$ & $\mathrm{A} 2$ & $\mathrm{~S}$ \\
\hline $4-2001$ & Snapdragon, A. majus & P. nicotianae & $10(10)$ & $\mathrm{A} 2$ & $\mathrm{~S}$ \\
\hline $5-2000$ & Fuchsia, Fuchsia spp. & P. nicotianae & $15(15)$ & $\mathrm{A} 2$ & $\mathrm{R}$ \\
\hline $6-2001$ & Vinca, Catharanthus roseus & P. nicotianae & $10(10)$ & A1 & $\mathrm{S}$ \\
\hline $7-2001$ & Verbena, Verbena hybrida & P. nicotianae & $12(8)$ & $\mathrm{A} 1$ & $\mathrm{~S}$ \\
\hline $7-2001$ & Bacopa, Sutera cordata & P. nicotianae & $20(10)$ & A1 & $\mathrm{S}$ \\
\hline $8-2001$ & Verbena, $V$. hybrida & P. nicotianae & $20(10)$ & A1 & $\mathrm{S}$ \\
\hline 9-2001 & African Violet, Saintpaulia ionantha & P. nicotianae & $30(10)$ & $\mathrm{A} 2$ & $\mathrm{~S}$ \\
\hline $10-2001$ & Dusty Miller, Cineraria maritima & P. nicotianae & $30(10)$ & $\mathrm{A} 2$ & $\mathrm{~S}$ \\
\hline $11-2001$ & Verbena, $V$. hybrida & P. nicotianae & $2(2)$ & $\mathrm{A} 1$ & $\mathrm{~S}$ \\
\hline
\end{tabular}

${ }^{\text {a }}$ Floriculture production facilities are identified by a number (1 to 11) followed by the year of sampling.

${ }^{b}$ Representative isolates from each set were identified to species by morphological criteria and the similarity of internal transcribed spacer region I and II DNA sequences to GenBank.

${ }^{c}$ The number of isolates characterized using amplified fragment length polymorphism markers is in parenthesis following the total number of isolates recovered and screened for mating type and mefenoxam sensitivity.

${ }^{\mathrm{d}} \mathrm{MR}=$ mefenoxam resistance, determined by in vitro screening on $100 \mathrm{ppm}$ a.i. amended media; $\mathrm{S}=<30 \%$ growth of control $(\mathrm{GC})$, IR $=$ between 30 and $90 \% \mathrm{GC}$ and $\mathrm{R}=>90 \% \mathrm{GC}$. 
to the cycling parameters outlined in the Microbial Fingerprinting protocol.

The selective primers EcoRI-AC and MseI-CA amplified between 50 and 70 clearly resolved markers for $P$. nicotianae and $P$. drechsleri which were used in this study. The EcoRI selective primer was labeled at the 5' end with carboxyfluorescein (FAM) dye. The fluorescent dye was excited by laser radiation and visualized by its characteristic absorption-emission frequency. Only the fragments containing an EcoRI restriction site were resolved.

Selective amplification AFLP products and a carboxy-X-rhodamine (ROX) size standard were loaded into each lane on a denaturing polyacrylamide gel and the fragments resolved in an ABI Prism 377 DNA Sequencer. Results were prepared for analysis in the form of electropherograms using GeneScan Analysis software (PE/ABI). AFLP fragments were scored manually as present $=1$ or absent $=0$ using Genotyper (PE/ABI).

AFLP fragments for each isolate were scored for presence or absence, and the binary data matrix was converted to a similarity matrix using a simple matching coefficient of resemblance with the program NTSYSpc (version 2.02k; Applied Biosta- tistics Inc., Exeter Software, Setauket, NY). Unweighted pair group method with arithmetic averages cluster analysis was performed on the similarity matrix and a tree was generated. Isolates with identical AFLP profiles were considered to be clones. Representatives of the clonal lineages were subjected to three separate DNA extractions and AFLP reactions.

\section{RESULTS}

Phytophthora isolates. Phytophthora isolates were recovered from eight hosts at 11 locations (Table 1). Disease symptoms commonly included stunting or wilting. Upon inspection of symptomatic plants, brown or black crown regions or significant root rot were observed. Morphological criteria and ITS sequence analysis identified $P$. nicotianae and $P$. drechsleri as the causal agents. $P$. nicotianae was recovered from eight locations from the following hosts: snapdragon, fuchsia, verbena, bacopa, vinca, African violet, and dusty miller. $P$. nicotianae isolates produced spherical sporangia with prominent papilla and short pedicels on water agar, amphigynous oospores in the presence of an opposite mating type (A1 or A2), and abundant chlamydospores on UCV8 agar after 3 to 5 days of incubation at room temperature $\left(23\right.$ to $\left.25^{\circ} \mathrm{C}\right) . P$. drechsleri isolates were recovered from two facilities producing poinsettias (Table 1). Sporangia produced on water agar were nonpapillate and isolates produced amphigynous oospores in the presence of an A1 or A2 $P$. capsici culture. No chlamydospores were observed on UCV8 agar after 3 to 5 days at room temperature $\left(23\right.$ to $\left.25^{\circ} \mathrm{C}\right)$ and growth was not inhibited at $35^{\circ} \mathrm{C}$.

Phenotypic diversity. All of the isolates collected from a particular facility had the same compatibility type and were equally sensitive or resistant to mefenoxam. Both the A1 and A2 compatibility types for $P$. nicotianae were detected during this study but occurred at different locations (Table 1). For $P$. drechsleri, only the A1 compatibility type was recovered. $P$. nicotianae isolates $(n=15)$ fully resistant to mefenoxam were recovered from fuchsia; all other $P$. nicotianae recovered from other hosts and production sites were fully sensitive to the fungicide. At one production site, all of the P. drechsleri isolates recovered were intermediately resistant to mefenoxam while the isolates from another production site were fully sensitive to mefenoxam.

Genetic diversity. There were a total of 68 AFLP markers resolved from the $P$.

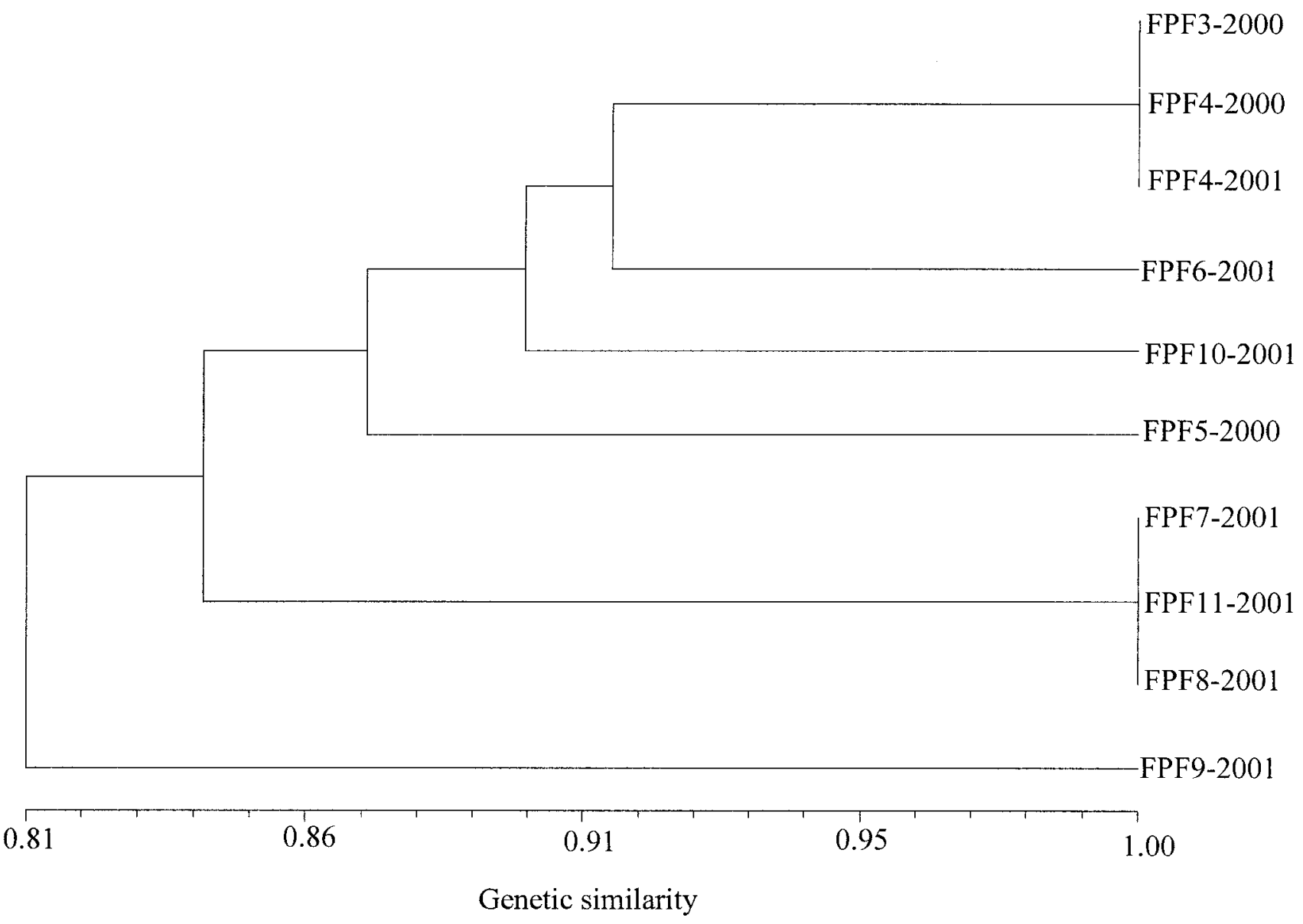

Fig. 1. Genetic similarity of Phytophthora nicotianae clonal lineages from floriculture production facilities (FPF) in the United States using 68 amplified fragment length polymorphism markers. Lineages are represented by a single isolate which is identified by location (FPF1 to FPF11) followed by the year of sampling. 
nicotianae isolates analyzed. Of these, 42 were present in every isolate (monomorphic) and 26 were present in some isolates and absent in others (polymorphic). For $P$. drechsleri, there were a total of 64 AFLP markers resolved, with 30 being monomorphic and 34 polymorphic. In every case, $P$. nicotianae and $P$. drechsleri isolates recovered from the same location, regardless of host, spatial location within the facility, or year, were identical. Over the 10 locations where $P$. nicotianae was recovered, six distinct clones were found (Fig. 1). There were two cases where members of the same clonal lineage of $P$. nicotianae were recovered at more than one location; production site locations 3 and 4 and production site locations 7, 8, and 11 (Fig. 1). Production sites 3 and 4 both received snapdragons as seedlings from the same producer in 2000. Production sites 8 and 11 both received verbena plants from production site 7 . Isolates recovered from field production site location 4 had identical phenotypic and AFLP profiles over 2 years of sampling (Fig. 1).

\section{DISCUSSION}

$P$. nicotianae and $P$. drechsleri were recovered from floriculture hosts at 11 locations in the eastern United States. At each of the locations, the isolates recovered had the same compatibility type, sensitivity to mefenoxam, and AFLP profile. AFLP markers provided a high level of genetic resolution, revealing six distinct clonal lineages of $P$. nicotianae and two clonal lineages of $P$. drechsleri. The lack of diversity among the Phytophthora isolates recovered within a facility suggests that spread was accomplished mainly by asexually generated propagules such as hyphal fragments, sporangia, chlamydospores, or zoospores.

In addition to the spread of clonal lineages within facilities, the background of locations 3 and 4 and that of locations 7, 8, and 11 are particularly interesting because single clonal lineages may have been spread among these facilities. The snapdragon producers at locations 3 and 4 purchased snapdragon plugs from the same supplier in 2000. All 195 P. nicotianae isolates from these two sites were identical for mating type and sensitivity to mefenoxam, and analysis of the DNA from 80 isolates revealed identical multilocus AFLP profiles for each of the isolates. While it is possible that the pathogen was introduced to locations 3 and 4 via infected plants, it is also possible that the disease was already established at these sites prior to the first plant sampling in 2000. The 10 samples recovered in 2001 from snapdragons at location 4 were identical to the isolates collected in 2000, indicating the potential for this pathogen to survive in the southeastern United States despite a nonhost fallow period and treatment with a fumigant (methyl bromide/chloropicrin). $P$. nicotianae produces abundant chlamydospores in infected tissue and this may have contributed to the survival of this clonal lineage from 2000 to 2001 (13).

The isolates recovered from locations 7 , 8 , and 11 were also identical and may be an example of how $P$. nicotianae may be spread within and among production facilities. Location 7 includes flowering potted plant crops such as verbena and bacopa, which are both propagated on site via cuttings. Rooted cuttings are sold to other growers who prepare them for direct sale or may pass them as prefinished plants on to wholesalers or other retailers. The finding that both locations 8 and 11 received verbena plants from location 7 and that the isolates recovered from all three locations were phenotypically and genotypically identical suggests that infected plant material may have carried $P$. nicotianae from location 7 to locations 8 and 11 .

Overall, it appears that asexual reproduction was the dominant, if not sole, means by which the epidemics in this study developed. Controlling the spread of Phytophthora spp. within and among production facilities can be a difficult task involving two major challenges. The first is ensuring that Phytophthora spp. are excluded from production sites. This is particularly difficult with floriculture hosts because of the widespread distribution of prefinished plants. In many cases, plants do not exhibit obvious symptoms until infection is well established or until the plants are placed under environmental stress (e.g., over- or under-watering). Ferrin and Rohde (6) discussed how infected plants treated with fungicides may appear healthy until the fungicides lose efficacy and pathogen populations increase (6). The second challenge is eradicating Phytophthora spp. once they have been introduced. Removing visibly diseased plants will not prevent spore production and spread from plants showing few if any symptoms. A control strategy that includes using absorption mats below pots to filter out recirculating inoculum (e.g., hyphal fragments and zoospores) may be helpful in such a situation (18). Adding calcium to water or nutrient solutions interferes with zoospores of $P$. parasitica at multiple stages and may be useful in limiting spread via recirculating irrigation solutions (19). Adding aluminum to peat-based soilless potting mixtures suppresses $P$. parasitica on Catharanthus roseus (vinca) $(1,8)$ and may provide a viable alternative in an integrated approach. Sanitizing the facility between crops is a standard recommendation to eliminate carryover, but disinfestation is often incomplete. For many growers, combating Phytophthora spp. remains an ongoing challenge despite close adherence to management recommendations. Although many of the production facilities included in this study employ PAFs, the mefenoxam-resistant clonal lineage recov- ered from location 5 suggests that this strategy may not prove effective in all cases.

\section{ACKNOWLEDGMENTS}

We thank M. Bour and P. Tambalam for laboratory assistance.

\section{LITERATURE CITED}

1. Benson, D. M. 1993. Suppression of Phytophthora parasitica on Catharanthus roseus with aluminum. Phytopathology 83:13031308.

2. Bernhardt, E. A., and Grogan, R. G. 1982. Effect of soil matric potential on the formation and indirect germination of sporangia of Phytophthora parasitica, Phytophthora capsici, and Phytophthora cryptogea rots of tomatoes, Lycopersicon esculentum. Phytopathology 72:507-511.

3. Cooke, D. E. L., Drenth, A., Duncan, J. M., Wagels, G., and Brasier, C. M. 2000. A molecular phylogeny of Phytophthora and related Oomycetes. Fungal Genet. Biol. 30:17-32.

4. Erwin, D. C., and Ribeiro, O. K. 1996. Phytophthora Diseases Worldwide. The American Phytopathological Society, St. Paul, MN.

5. Ferrin, D. M., and Kabashima, J. N. 1991. Invitro insensitivity to metalaxyl of isolates of Phytophthora citricola and P. parasitica from ornamental hosts in southern California. Plant Dis. 75:1041-1044.

6. Ferrin, D. M., and Rohde, R. G. 1992. Population dynamics of Phytophthora parasitica, the cause of root and crown rot of Catharanthus roseus, in relation to fungicide use. Plant Dis. 76:60-63

7. Ferrin, D. M., and Rohde, R. G. 1992. In-vivo expression of resistance to metalaxyl by a nursery isolate of Phytophthora parasitica from Catharanthus roseus. Plant Dis. 76:8284.

8. Fichtner, E. J., Hesterberg, D. L., and Shew, H. D. 2001. Nonphytotoxic aluminum-peat complexes suppress Phytophthora parasitica. Phytopathology 91:1092-1097.

9. Fry, W. E., Goodwin, S. B., Matuszak, J. M. Spielman, L. J., Milgroom, M. G., and Drenth, A. 1992. Population genetics and intercontinental migrations of Phytophthora infestans. Annu. Rev. Phytopathol. 30:107129.

10. Goodwin, S. B. 1997. The population genetics of Phytophthora. Phytopathology 87:462473.

11. Lamour, K. H., and Hausbeck, M. K. 2000. Mefenoxam insensitivity and the sexual stage of Phytophthora capsici in Michigan cucurbit fields. Phytopathology 90:396-400.

12. Lamour, K. H., and Hausbeck, M. K. 2001 Investigating the spatiotemporal genetic structure of Phytophthora capsici in Michigan. Phytopathology 91:973-980.

13. Lutz, A. L., and Menge, J. A. 1991. Population fluctuations and the numbers and types of propagules of Phytophthora parasitica that occur in irrigated citrus groves. Plant Dis. 75:173-179.

14. McDonald, B. A. 1997. The population genetics of fungi: tools and techniques. Phytopathology 87:448-453.

15. Neher, D., and Duniway, J. M. 1992. Dispersal of Phytophthora parasitica in tomato fields by furrow irrigation. Plant Dis. 76:582586.

16. Strong, S. S., Behe, B. K., Deneke, C. F., Bowen, K. L., and Keever, G. J. 1997. Cultivar and spacing effects on transmission of Phytophthora parasitica in an ebb-and-flow subirrigation system. Plant Dis. 81:89-95.

17. Timmer, L. W., Graham, J. H., and Zitko, S E. 1998. Metalaxyl-resistant isolates of Phy- 
tophthora nicotianae: occurrence, sensitivity, and competitive parasitic ability on citrus. Plant Dis. 82:254-261.

18. Van der Gaag, J. D., Kerssies, A., and Lanser, C. 2001. Spread of Phytophthora root and crown rot in Saintpaulia, Gerbera and Spathiphyllum pot plants in ebb-and-flow-systems. Eur. J. Plant Pathol. 107:535-542.
19. von Broembsen, S. L., and Deacon, J. W. 1997. Calcium interference with zoospore biology and infectivity of Phytophthora parasitica in nutrient irrigation solutions. Phytopathology 87:522-528.

20. Vos, P., Hogers, R., Bleeker, M., Reijans, M., van der Lee, T., Hornes, M., Frijters, A., Pot, J., Peleman, J., Kuiper, M., and Zabeau, M.
1995. AFLP: a new technique for DNA fingerprinting. Nucleic Acids Res. 23:44074414.

21. Yoshimura, M. A., Uchida, J. Y., and Aragaki, M. 1985. Etiology and control of poinsettia blight caused by Phytophthora nicotianae var. parasitica and $P$. drechsleri. Plant Dis. 69:511-513. 